\title{
A rare and life-threatening but treatable cause of intractable vomiting: A case report on superior mesenteric artery syndrome
}

\author{
Alvin Oliver Payus ${ }^{1}$, Muhammad Firdaus Abdul Rahim ${ }^{2}$, Rabani Remli ${ }^{2}$ \\ (1) Faculty of Medicine and Health Science, Universiti Malaysia Sabah, Internal Medicine, KOTA KINABALU, Malaysia \\ (2) Department of Medicine, Universiti Kebangsaan Malaysia Medical Centre, Internal Medicine, KUALA LUMPUR, \\ Malaysia
}

Date submitted:

Jan 28, 2019

Date accepted:

May 10, 2019

Online publication date:

December 15, 2019

\section{Corresponding Author:}

Alvin Oliver Payus

Faculty of Medicine and Health

Science, Universiti Malaysia

Sabah, Internal Medicine, KOTA

KINABALU, Malaysia

dralvinpayus@ums.edu.my

Keywords: Superior mesenteric artery syndrome, duodenal obstruction, vomiting, electrolytes imbalance.

\begin{abstract}
Superior mesenteric artery (SMA) syndrome is a rare cause of gastro-duodenal obstruction which results from aortomesenteric space narrowing that lead to duodenal compression. This gastro-vascular condition is highly morbid, but yet potentially treatable if the appropriate treatment initiated on time. Here, we report a case of SMA syndrome that present with intractable vomiting and severe electrolytes imbalance. Despite having stormy presentation, the patient improved after aggressive resuscitations and supportive management. The objective of this case report is to share the uncommon occurrence of SMA syndrome, and to enlighten that although fatal, it is potentially treatable with aggressive supportive management.
\end{abstract}

\section{Introduction}

Superior Mesenteric Artery (SMA) syndrome is a small bowel obstruction of the third part of duodenum due to compression at the acute angle in between the descending aorta and the superior mesenteric artery that follows rapid weight loss resulting in a lack of retroperitoneal and visceral fat. Recognizing SMA syndrome in a patient with recurrent vomiting poses a great challenge that requires a high index of suspicion among the treating clinicians. And although fatal, it is a potentially treatable condition.

\section{Presentation of Case}

A 23-year old army man who was a smoker and has no known medical illness came to the emergency department with one-month history of intractable vomiting episodes. The nature of his vomiting was always post-prandial, contained recent food, occurred up to six episodes per day and associated with cramping sensation over his upper and lower limbs. On further questioning, he admitted to having a mild epigastric discomfort and has been passing motion less frequent than usual. He also lost about $10 \mathrm{~kg}$ of weight for the past one month. Upon clinical assessment, he was thin with the body weight of $45 \mathrm{~kg}$, very lethargic and tachypnoeic. His abdomen was soft, not tender and not distended on palpation. There was no palpable organomegaly and the bowel sound was active. Examination of cardiorespiratory system was unremarkable, and there was no lymphadenopathy, no evidence of oral thrush and no Cushingoid facies. An electrocardiogram on presentation showing prolonged QT-segment interval, with the QTc value stands at 620 milliseconds. Initial blood investigations were taken and shows hypokalaemia with potassium of $2.3 \mathrm{mmol} / \mathrm{L}$ (normal=3.5 to $4.5 \mathrm{mmol} / \mathrm{L}$ ), hypophosphatemia with serum phosphate of 0.77 $\mathrm{mmol} / \mathrm{L}$ (normal=1.12 to $1.45 \mathrm{mmol} / \mathrm{L}$ ), and hypocalcaemia with corrected serum calcium of $2.04 \mathrm{mmol} / \mathrm{L}$ (normal=2.12 to 2.65 $\mathrm{mmol} / \mathrm{L}$ ). He also developed acute kidney injury as evidence by raised serum urea and creatinine (urea $=17 \mathrm{mmol} / \mathrm{L}$, normal=6 to $10 \mathrm{mmol} / \mathrm{L}$; creatinine $=363 \mu \mathrm{mol} / \mathrm{L}$, normal $=60$ to 120 $\mu \mathrm{mol} / \mathrm{L}$ ). His bilirubin was elevated (total bilirubin $=45 \mu \mathrm{mol} / \mathrm{L}$, normal $=5$ to $12 \mu \mathrm{mol} / \mathrm{L}$ ) but otherwise his was normal and there was no transaminitis and alkaline phosphatase was not raised. His arterial blood gas shows metabolic alkalosis with respiratory compensation $(\mathrm{pH}=7.56$, normal=7.35 to $7.45 ; \mathrm{pCO} 2=72$ 
$\mathrm{mmHg}$, normal $=35$ to $45 \mathrm{mmHg}$; serum bicarbonate $=62 \mathrm{mEq} / \mathrm{L}$, normal=22 to $26 \mathrm{mEq} / \mathrm{L}$ ). Unfortunately, during the early hours of assessment, he developed generalized tonic-clonic seizure with cardiac rhythm of ventricular fibrillation and went into asystole. He survived after 70 minutes of resuscitation and was admitted to intensive care unit for stabilization. An urgent contrast enhanced computed tomography of the abdomen was done and showed that the stomach was distended and elongated. The third segment of duodenum was small in calibre at the pre-caval and pre-aortic region and the lack of mesenteric fat between this area was evident. The aorto-mesenteric angle and aorto-mesenteric distance reduced, only measuring $15.6^{\circ}$ and $7.3 \mathrm{~mm}$ respectively (Figure 1 ). Nevertheless, intraluminal

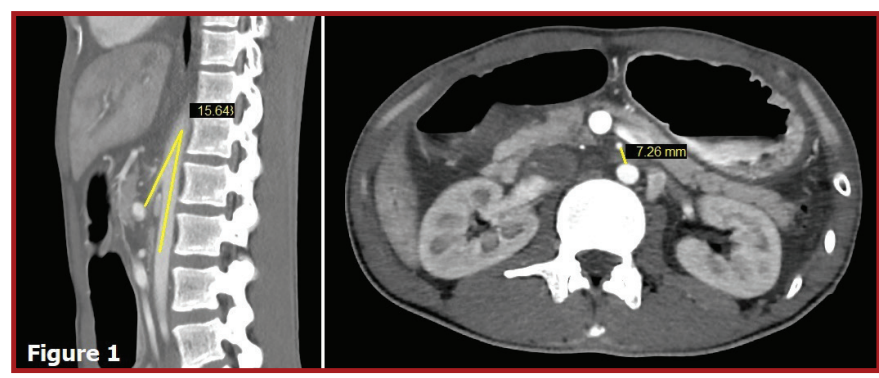

Figure 1. Left: Sagittal view of contrast enhanced computed tomography scan of the aorta and the superior mesenteric artery showing a narrowed aortomesenteric angle of $15.6^{\circ}$. Right: Axial view showing a shortened aorta-superior mesenteric artery distance of $7.3 \mathrm{~mm}$.

contrast could still be seen opacifying the duodenum, jejunum and ileal loops. On top of that, no proximal dilatation over the first and second segment of the duodenum. His initial management step was challenging due to acute kidney injury due to hypotensive acute tubular necrosis. There was no urine output despite rigorous intravenous fluid therapy, hence he was started on haemodialysis support. After one week of aggressive supportive management. he was able to be weaned off from the ventilator. His Glasgow Coma Scale was full, but his eye examination revealed a vertical gaze marked on looking down. He has no confusion and no ataxia. Hence, complex ophthalmoplegia of Wernicke's syndrome was suspected, likely due to thiamine loss during the long-standing vomiting. The symptoms resolved after thiamine replacement in the form of IV Parentrovite. Subsequent oesophagoduedenoscopy was done when he was more stable and revealed narrowing of the duodenum. Nasojejunum tube for feeding was inserted at the same setting. He was subjected for high protein and caloric diet for weight gain. The patient currently improved clinically, ambulating and gradually gaining weight.

\section{Discussion}

Superior Mesenteric Artery (SMA) syndrome was first described in 1861 by Von Rokitansky and was further elaborated in detail by $\mathrm{D}$. Wilke on the pathophysiological findings (1), and hence its eponymous name. It is uncommon and the exact incidence is unknown. It is a resultant of loss of mesenteric fat pad followed by the loss of space in between the aorta and superior mesenteric artery, which subsequently causes compression of the third portion of the duodenum in the tight space. There are many causes of SMA syndrome that were sporadically cited in the literature, which include rapid and severe weight loss due to anorexia nervosa, burns, after prolonged bed rest, just to name a few (2). It can also occur following correction of vertebral deformity, and have been reported to occur in patient with spinal cord injury during their rehabilitation period (3). The symptoms might be insidious; hence this emphasizes that comprehensive history is paramount in aiding clinical evaluation. The diagnostic imaging of choice would be coloured Doppler ultrasound or multi-slice abdominal computed tomography (CT) imaging (4). The early measures in management would be correction of electrolyte imbalance and gastrointestinal decompression, followed by nasojejunum tube placement to support aggressive and high calorie feeding, with the preliminary aim of weight gain. Should conservative treatment attempted but to no avail,

\begin{tabular}{lcc|}
\hline Investigations & Result & Normal range \\
\hline Haemoglobin & $15.8 \mathrm{~g} / \mathrm{dL}$ & $12-18 \mathrm{~d} / \mathrm{dL}$ \\
\hline Platelet & $424 \times 10^{9} / \mathrm{L}$ & $150-400 \times 10^{9} / \mathrm{L}$ \\
\hline Total white cell & $13.6 \times 10^{9} / \mathrm{L}$ & $4.0-11.0 \times 10^{9} / \mathrm{L}$ \\
\hline Bilirubin & $45 \mu \mathrm{mol} / \mathrm{L}$ & $<13 \mu \mathrm{mol} / \mathrm{L}$ \\
\hline Alanine Transaminase & $31 \mathrm{U} / \mathrm{L}$ & $<35 \mathrm{U} / \mathrm{L}$ \\
\hline Alkaline Phosphatase & $97 \mathrm{U} / \mathrm{L}$ & $30-150 \mathrm{U} / \mathrm{L}$ \\
\hline Amylase & $180 \mathrm{U} / \mathrm{L}$ & $<220 \mathrm{U} / \mathrm{L}$ \\
\hline pH & 7.56 & $7.35-7.45$ \\
\hline Bicarbonate & $62 \mathrm{mEq} / \mathrm{L}$ & $22-26 \mathrm{mEq} / \mathrm{L}$ \\
\hline pCO2 & $72 \mathrm{mmHg}$ & $35-45 \mathrm{mmHg}$ \\
\hline Sodium & $136 \mathrm{mmol} / \mathrm{L}$ & $135-145 \mathrm{mmol} / \mathrm{L}$ \\
\hline Potassium & $2.3 \mathrm{mmol} / \mathrm{L}$ & $3.5-4.5 \mathrm{mmol} / \mathrm{L}$ \\
\hline Urea & $17 \mathrm{mmol} / \mathrm{L}$ & $6-10 \mathrm{mmol} / \mathrm{L}$ \\
\hline Creatinine & $363 \mu \mathrm{mol} / \mathrm{L}$ & $60-120 \mu \mathrm{mol} / \mathrm{L}$ \\
\hline Corrected Calcium & $2.04 \mathrm{mmol} / \mathrm{L}$ & $2.12-2.65 \mathrm{mmol} / \mathrm{L}$ \\
\hline Phosphate & $0.77 \mathrm{mmol} / \mathrm{L}$ & $1.12-1.45 \mathrm{mmol} / \mathrm{L}$ \\
\hline Magnesium & $1.01 \mathrm{mmol} / \mathrm{L}$ & $0.75-1.05 \mathrm{mmol} / \mathrm{L}$ \\
\hline Albumin & $47 \mathrm{~g} / \mathrm{L}$ & $35-50 \mathrm{~g} / \mathrm{L}$ \\
\hline
\end{tabular}


surgical intervention may be required.

The differential diagnosis of SMA syndrome includes all other causes of duodenal obstruction, including mechanical obstruction secondary to peptic ulcer disease, or duodenal ileus causing megaduodenum such as diabetes mellitus. It is also important to differentiate SMA syndrome from chronic idiopathic intestinal pseudo-obstruction, and also non-organic cause such as bulimia nervosa.

In our patient, the aortomesenteric angle and aortomesenteric distance on multi-slice CT scan were markedly reduced from that of a normal anatomy, which normally range between $25^{\circ}$ to 60 and $10 \mathrm{~mm}$ to $28 \mathrm{~mm}$, respectively (5). This case is a well-illustrated clinical scenario during which we are faced with diagnostic uncertainty to commit with the SMA syndrome diagnosis due to its rarity, although the amalgam of history and radiological evidence were staring at us. As he collapsed and developed arrhythmia as a consequence of recurrent intractable vomiting, we screened for possibilities of rare infections such as Rickettsia and Lyme disease which turned up to be all negative. We also screened for possibilities of autoimmune diseases which also turned out to be negative. We performed a thorough investigations for other differentials as SMA syndrome is a rare cause and on top of that, the patient was so unwell upon presentation that he developed cardiac arrested as a result of the severe metabolic alkalosis. His ECG showed widely prolonged QT-interval that consistent with hypokalemia and hypocalcemia which were corrected accordingly. He showed dramatic improvement after aggressive supportive management and recovers without requiring surgical intervention. He is currently on high caloric and protein diet via nasojejunal tube feeding for weight gain.

\section{Conclusion}

In conclusion, this case report demonstrates the very severe end spectrum of SMA syndrome, which highly fatal, yet potentially treatable if the proper treatment initiated early. Thus, high index of suspicion based on history and clinical evaluation is very important in order to avoid preventable mortality.

\section{Acknowledgments}

The authors would like to thank the patient and his family for their cooperation in relation to the writing of this report. The authors would also like to thank the Director General of Health Malaysia for his permission to publish this article.

\section{Conflict of Interest}

The authors declared they do not have anything to disclose regarding conflict of interest with respect to this manuscript.

\section{References}

1. Gniftiths GJ, Whitehouse GH, Wilkie DP. Chronic duodenal ileus. Br J Surg. 1921(9):204.

2. Ugras M, Bicer S, Coskun FT, Romano E, Ekci B. Superior mesenteric artery syndrome: A rare but life threatening disease. Turkish journal of emergency medicine. 20171;17(2):70-72.

3. Laffont I, Bensmail D, Rech C, Prigent G, Loubert G, Dizien $O$. Late superior mesenteric artery syndrome in paraplegia: case report and review. Spinal cord. 2002;40(2):88.

4. Santer R, Young C, Rossi T, Riddlesberger MM. Comput- ed tomography in superior mesenteric artery syndrome. Pediatric radiology. 19911;21(2):154-155.

5. Singal R, Sahu PK, Goel M, et al. Superior mesenteric artery syndrome: A case report. North American journal of medical sciences. 2010;2(8):392-394. 